\title{
Shaping Student Confidence and Their Perception of Learning in Undergraduate Chemistry and Biochemistry Courses
}

Manuscript type: Article

Shortened title: Shaping student confidence and learning perceptions in chemistry

\author{
Author \\ Timothy M. Gould

\begin{abstract}
Affiliations
Colorado College, Department of Chemistry and Biochemistry, Colorado Springs, CO 80903. Correspondence to: tgould@coloradocollege.edu
\end{abstract}

\section{Keywords}

Student confidence, perception of learning, small group work, multistage assessment, class environment, instructor feedback, active learning

\section{Competing Interests}

There are no competing interests. 


\begin{abstract}
This study examined factors influencing student confidence and their perception of learning in the context of undergraduate chemistry and biochemistry courses. Anonymous online surveys were used to measure the extent to which small group work influenced student confidence in solving problems compared to working individually, as well as how various course factors and the amount of effort and pleasure students experienced during their coursework influenced their perception of learning. Upon examining over 2500 student responses to more than 150 unique problems/exercises across 3 different courses, student confidence in solving problems improved to an average of approximately 8 out of 10 when they worked in small groups, compared to that of 6.5 out of 10 when working alone. Students ranked (i) opportunities to revisit assessments, (ii) the class environment, and (iii) instructor feedback as course factors that were most influential on their learning. There was little if any correlation between student effort and their perception of learning, and their perception of learning only slightly correlated with the amount of pleasure they experienced during their coursework. Taken together, these data highlight the importance of facilitating regular small group work, multistage assessments, good feedback and a pleasurable learning environment for students.
\end{abstract}




\section{Introduction}

Many people believe that motivation drives action, yet in practice the opposite is true (Burns, 1981). The decision to act has been shown to be closely linked with one's confidence in their decision (Kepecs, Uchida, Zariwala, \& Mainen, 2008; Kiani \& Shadlen, 2009). Evidence also suggests that confidence expectations affect future decision-making (Boldt, Schiffer, Waszak, \& Yeung, 2019). Thus, increasing student confidence in their academic activities is almost certain to increase the likelihood that they will attempt such activities in the future. The relationship between practice and the development of expertise has been well-characterized, i.e., "deliberate practice" (Ericsson, Krampe, \& Tesch-Romer, 1993). Hence it follows that increasing student confidence should also build their expertise through increased practice. Naturally, the question arises - how can instructors help build student confidence in their academic activities? Adding group members to work on problems decreased overconfidence in intellective tasks (Zarnoth \& Sniezek, 1997), and student confidence increased when learning was inquiry-based (Cook, Snow, Binns, \& Cook, 2015), when content was relevant to authentic, real-world problems such as the COVID-19 pandemic (Anderson, Justement, \& Bruns, 2020), and when guidance was gradually decreased to promote independent decision-making (Kempton, Weber, \& Johnson, 2017). These findings are instructive as they identify key factors that instructors can incorporate as part of course learning experiences to help build student confidence.

One part of this study examined the extent to which small group work influences student confidence in solving problems within undergraduate chemistry and biochemistry courses. It was expected that for a sizeable fraction of students group work would mostly increase (or at least not decrease) their confidence in solving problems compared to working 
individually; remarkably, this was the case in almost all ( 95\%) instances. Another aspect of this work sought to characterize how specific course features and practices influence student perceptions of their learning. It is important to note that perception of learning is not the same as actual learning, and this study did not make any attempt to measure actual learning.

Objective measures of actual learning show that "active" methods, in which students directly engage in answering questions or solving problems in class with instructors providing timely feedback, clearly outperform traditional lecture-based approaches (Deslauriers, Schelew, \& Wieman, 2011; Freeman et al., 2014). There is a myriad of research-about 1,000 published studies - generally consistent with these findings. Yet student perceptions of learning do not always correlate with actual learning gains (Deslauriers, McCarty, Miller, Callaghan, \& Kestin, 2019), which can thus lead to a misleading narrative associated with the use of active learning methods. Additionally, this study separated different course factors and examined the degree to which each factor contributed to student perceptions of learning. The results are useful because the factors which were identified as more influential may be leveraged to increase student belief in the effectiveness of active learning methods. Finally, this study looked at possible relations between student perceptions of learning and the amount of effort and pleasure that they experienced during their coursework. It was expected that there would be some relationship between student perceptions of learning and the amount of effort they make based on the "deliberate practice" premise, i.e., that the amount of practice (effort) one makes and the expertise (learning) they develop are positively related. Thus, it was surprising to find little if any correlation between student perceptions of learning and the level of effort/difficulty 
that they experienced in their coursework. On the other hand, student perceptions of learning correlated very slightly with the amount of pleasure that they experienced. 


\section{Methods}

This study was determined as exempt educational research by the Colorado College Institutional Review Board because data collection was anonymous without involving grades. Anonymous online surveys were designed to measure students' self-reported levels of confidence in solving problems when working individually compared to that in small groups. Students were first asked to solve problems on their own as a homework assignment for an unspecified amount of time. The following day, students discussed their strategies and solutions to such problems together in class in small groups with their peers. Each small group contained 3-4 students and each group discussed one problem at a time for approximately 5-10 minutes while each class covered roughly 5-7 problems in total. Immediately after each class, students were emailed a link to an online survey in which they were asked to rank their confidence in solving the problems both before and after working in their small groups. The metric for confidence was measured as a rating on a scale from 0 to 10 , with 0 meaning no confidence and 10 meaning full confidence. Altogether the surveys examined student confidence in solving 153 unique problems discussed over dozens of classes involving 3 different undergraduate chemistry courses. Two of the courses covered five separate sections of first- and second-semester general chemistry (mostly first-year undergraduates), and one course covered first-semester biochemistry (largely third- and fourth-year undergraduates).

At the end of each course, a separate anonymous online survey was used to examine the extent to which various course feature/practices (factors) influenced student perceptions of their learning. Eight specific factors were examined including: (1) opportunities to revisit assessments, e.g., multistage exams/quizzes, (2) instructor feedback, (3) class environment, 
e.g., attitudes of instructor/TAs/peers, (4) questions requiring one to synthesize concepts and explain reasoning, (5) small group work, (6) synchronous class-wide discussions, (7) regular homework, and (8) asynchronous remote discussions. Students were asked to rank the degree to which each of these eight factors influenced their perceived learning on a scale from 0 to 10 , with 0 meaning no influence and 10 meaning maximum influence. Additionally, students were asked to pick/rank the top three of these eight factors that were the most influential on their learning experience.

As part of the same end-of-course survey, students were asked to rate the overall efficacy of their learning experience in the course on a scale from 0 to 10 , with 0 meaning no learning/completely ineffective and 10 meaning maximally effective learning. All classes were approximately 2 hours long, and students were also asked to estimate how much time they spent studying outside class each day to the nearest half-hour. Students were asked to rate the amount of effort (or relative difficulty) and pleasure they experienced both participating in class as well as that studying outside class each day. Options for relative difficulty/effort experienced ranged from extremely hard, hard, neither hard nor easy, easy, to effortless; that for pleasure ranged from extremely pleasurable, pleasurable, neither pleasurable nor displeasurable, displeasurable, to extremely displeasurable. The relative effort and pleasure ratings were coded numerically from 1 to 5 , with higher numbers corresponding to greater amounts of effort or pleasure. The in-class ratings were multiplied by the 2 hours spent in class each day, and the out-of-class ratings were multiplied by how much time students reported studying outside of class each day. The in-class and out-of-class ratings were summed to get a total daily score for effort and pleasure, which were then plotted against their overall rating for perceived learning. 


\section{Results}

$\underline{\text { Small group work enhances student confidence in solving problems }}$

The first research question asked - to what extent does small group work affect student confidence in solving problems compared to working individually? Figure 1 shows the degree to which small group work improved student confidence, and the data are shown as histograms so that one can appreciate the distribution of the effect. This dataset includes 2,796 paired responses with each set of responses corresponding to a single student's confidence in one problem before and after group work. A statistical comparison of the paired before versus after group work responses results in a very small $p$ value $(<0.00001)$, thus the group work effect is highly significant as is apparent from the histograms. On average individual student confidence in solving problems before group work was 6.55 out of 10 , and that after group work was 8.04 out of 10 . Hence small group work increased student confidence by roughly $23 \%$ on average in the aggregate. Moreover, examining how student confidence changed for each problem (Figure 1b), i.e., looking at each student's paired responses and noting whether their confidence increased, decreased, or did not change, student confidence increased after group work in $71 \%$ of cases. There were relatively few cases ( $5 \%$ of all responses) in which student confidence decreased after group work. In $24 \%$ of cases student confidence levels did not change, yet it is important to note that for nearly half of such cases (11\%) students were already fully confident before group work. 
a

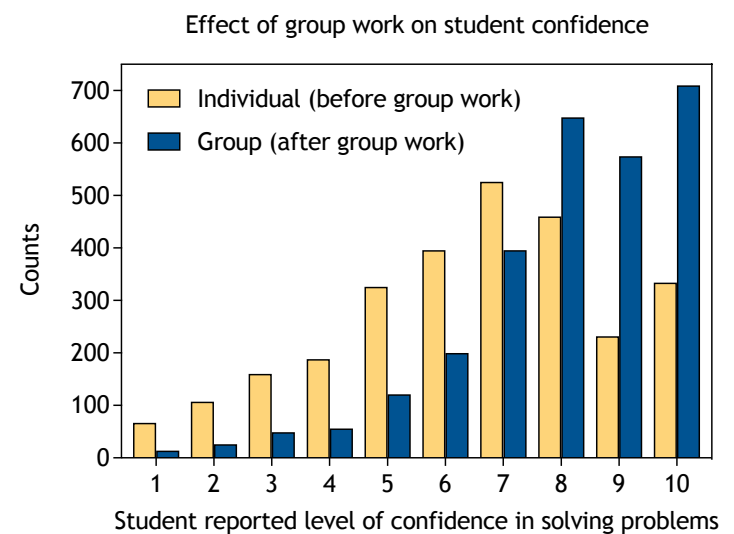

b

How student confidence in solving problems changes after group work

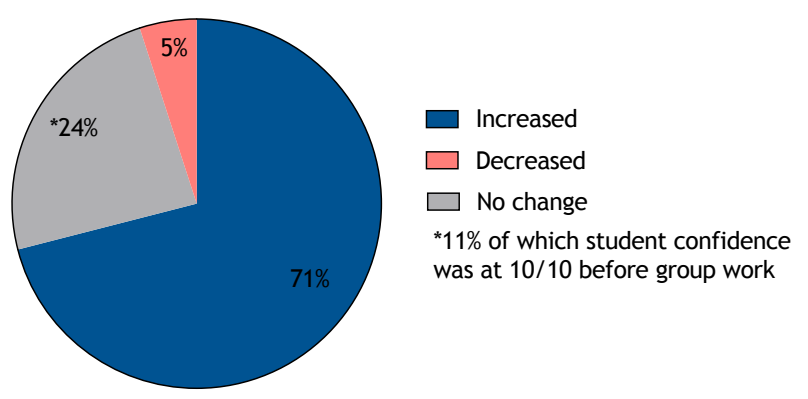

$\%$ of all responses (total=2,796)

Figure 1. Small group work improves student confidence in solving problems compared to working individually. (a) Histograms show student-reported levels of confidence in solving problems before (yellow) and after (blue) group work; data include over 2,796 paired responses to 153 different problems posed across 3 different courses ( 7 courses in total). (b) Pie chart shows how student confidence changed for each student/exercise after group work, i.e., whether it increased (blue), decreased (red), or did not change (gray).

\section{Factors influencing student perceptions of learning}

Students were asked to rate 8 different course features/practices (factors) in terms of how much they perceived each to contribute to their learning experience. It may be helpful first to elaborate briefly on the nature of some factors for clarity. Opportunities to revisit assessments included multistage quizzes or exams, in which students first attempted an assessment and were then given written instructor feedback to which they could respond and resubmit another attempt for additional credit at a later point in the course. Small group work involved groups of 3-4 students working in synchronous remote classes, during which each group spent approximately 5-10 minutes working on problems. Regular homework involved problems sets and associated readings given as an individual assignment that students were to complete prior to class; such assignments were graded based on effort/completion only. Asynchronous remote discussions were online threads accessible to the whole class in which 
students commented on their daily reading assignments, noting what they found most interesting, fascinating, or remarkable and why, as well as what they found most difficult, confusing, or counter-intuitive and why. Figure 2 shows the extent to which each factor influenced student perceptions of their learning. The factors are ordered from highest to lowest (left to right, respectively) based on relative levels of influence reported by students. Of all factors examined, students reported that opportunities to revisit assessments influenced their learning the most. The set of factors including class environment, instructor feedback, and questions requiring one to synthesize concepts and explain reasoning, were also highly influential on student learning perceptions. Asynchronous remote discussions were clearly least influential on most student-perceived learning experiences.

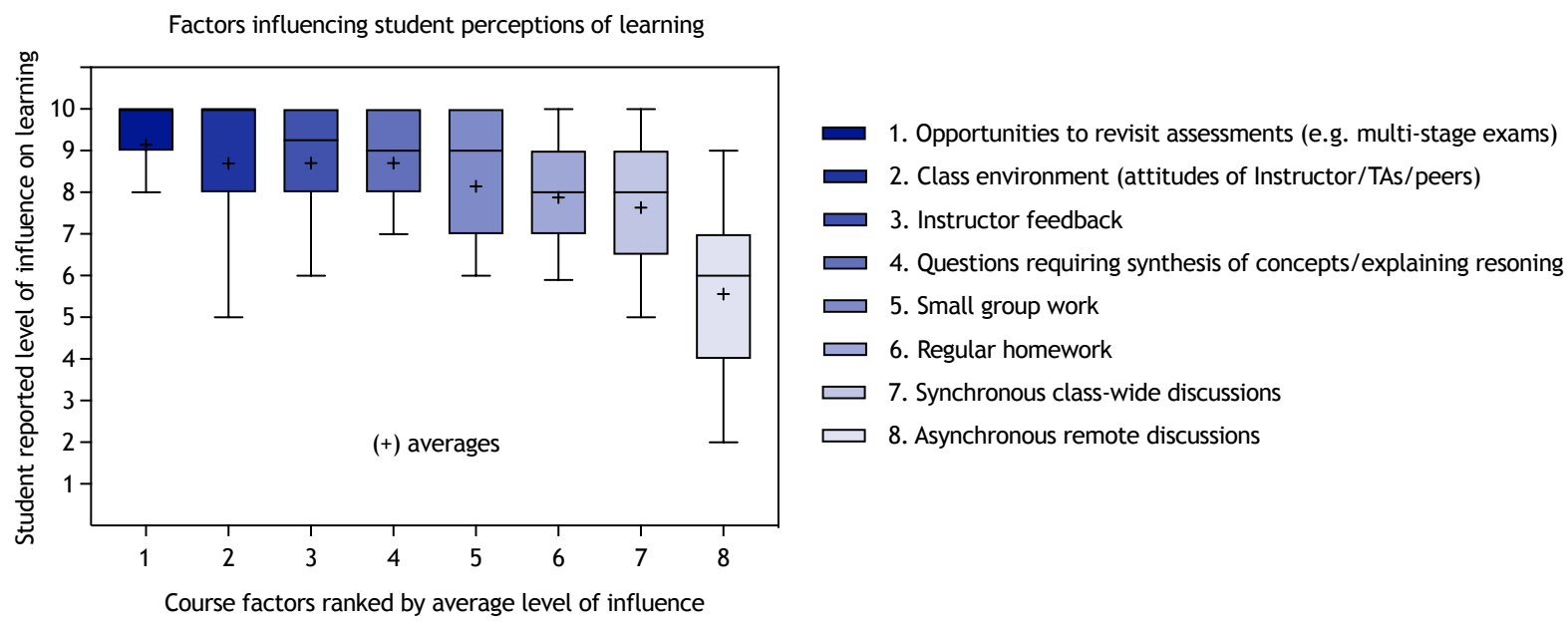

Figure 2. Revisiting assessments is highly influential on student perceptions of their learning. Box plots show the degree to which various course factors influenced student perceptions of their learning. Data include aggregate responses from 49 different students across 3 different courses. Factors are ordered/numbered from left to right (dark to light blue, respectively) based on the student-reported level of influence that each factor had on their learning. Horizontal lines within boxes indicate median values and $(+)$ signs indicate averages. 
$\underline{\text { Student perceptions of learning do not necessarily correlate with their efforts }}$

Students reported on the overall perceived effectiveness of their learning experience in courses, as well as the relative amount of effort and pleasure they experienced in their coursework. Student ratings of effort and pleasure were quantified by numerically coding responses to generate a metric for total daily effort and pleasure experienced both in and outside of class (described in Methods section). Figure 3 shows the relative amount of effort students experienced versus how much they perceived to learn, as well and the relative amount of pleasure they experienced versus how much they perceived to learn. Practically no correlation was observed between the level of student effort and their perception of learning, while only a very weak correlation was apparent between student perceptions of learning and the degree of pleasure that they experienced during their coursework.
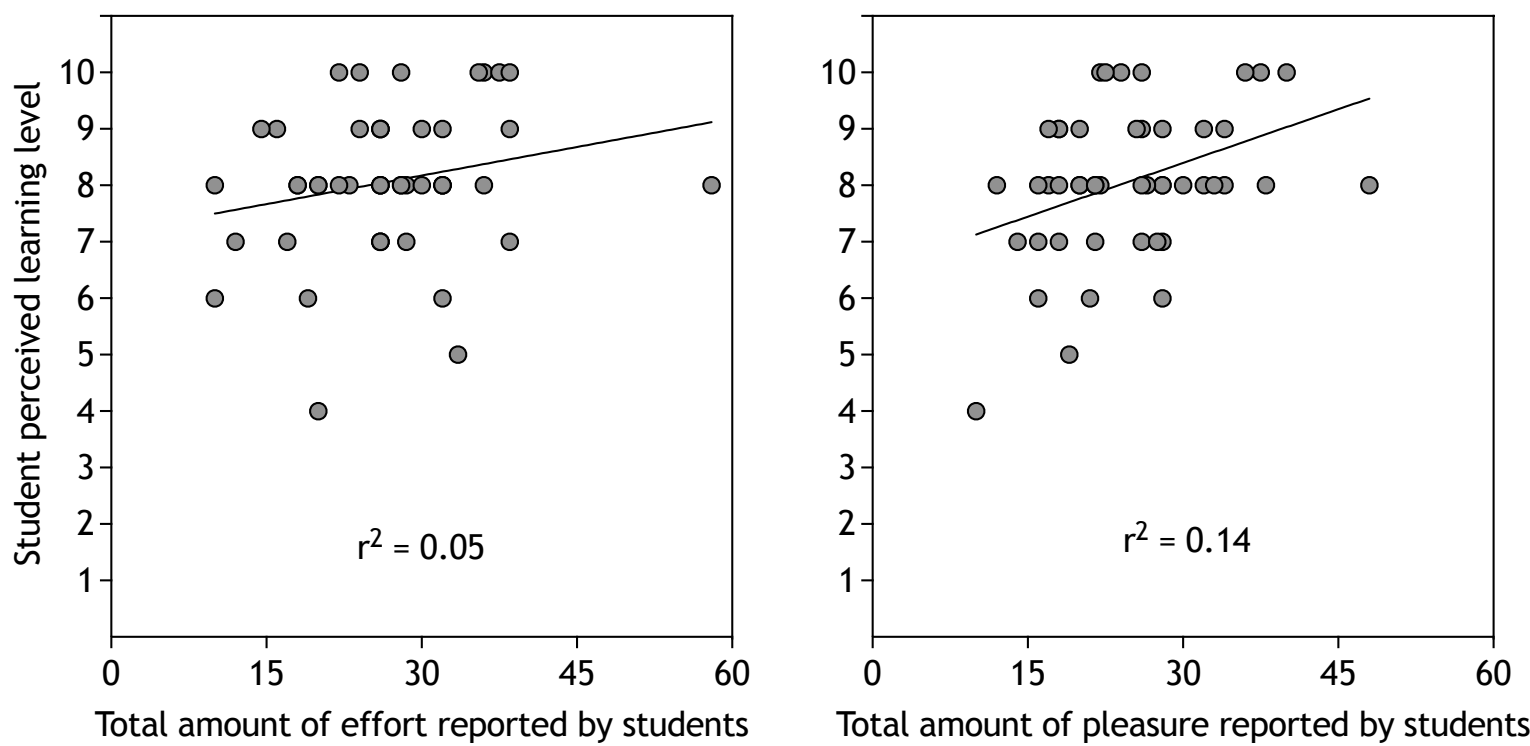

Figure 3. Student perceptions of learning do not correlate with their level of effort. Scatter plots show overall student perceived learning levels in courses versus the relative amount of effort (left) and pleasure (right) that they experienced during their coursework. Data include responses from 47 different students across 3 different courses. 


\section{Discussion}

While this study did not measure actual student learning or performance, others have established that small group work improves student performance in the context of universitylevel science courses (Gaudet, Ramer, Nakonechny, Cragg, \& Ramer, 2010). The increased performance of small groups is likely due to a collective intelligence factor at play in groups but not individuals (Woolley, Chabris, Pentland, Hashmi, \& Malone, 2010). This study demonstrates yet another important benefit of small group work, i.e., that it builds student confidence. As mentioned in the introduction, building student confidence will make students more likely to engage in future academic activities, which in turn gets them engaged and practicing more, thus eventually improving their level of expertise. While the confidence of university science students may correlate with their performance or correctness in some cases (Favazzo, Willford, \& Watson, 2014; Flanagan \& Einarson, 2017), it is also important to note that cognitive bias may skew the accuracy of this relationship, particularly with novice learners (Kruger \& Dunning, 1999). Thus, one should be cautious not to overinterpret student confidence as a metric for actual learning.

In this study it was rather surprising that group work increased student confidence so universally, especially considering that for about half of the cases in which student confident did not change after group work it was because such students were already fully confident prior to group work. While the group effect may be partially due to students simply having more time to consider problems, and/or partly biased by occasional instructor feedback during small group work, it is unlikely that such potentially confounding factors entirely account for the effect demonstrated here. Collective intelligence that arises in groups is at least one plausible 
explanation for why student confidence increased after group work, since it may bring additional information to light which reduces students' uncertainty in their solutions. This collective intelligence factor is largely dependent on the proportion of females, extent of cooperativity and social perceptiveness at play within groups (Riedl, Kim, Gupta, Malone, \& Woolley, 2021). Additionally, group members can provide validating feedback to one another, which may also increase their confidence in solutions. Remarkably, it was recently shown that scientific experts consistently make twenty-nine specific types of decisions in the process of solving authentic problems, irrespective of their discipline (Price, Kim, Burkholder, Fritz, \& Wieman, 2021). While this number of decisions is tractable, it is not few. Groups may also simply raise the likelihood that more of the decisions required to solve problems will be made. Even for the relatively few cases in which student confidence decreased after group work, it nevertheless may be useful to know what caused this. Therefore, future studies may be needed to identify students for whom confidence decreases after group work and inquire with them as to why/how that happens.

Examining how specific course factors influence student perceptions of learning within the context of courses that use active learning methods is useful because instructors can leverage more influential factors to increase student belief in the efficacy of active learning. This study showed that students perceived opportunities to revisit assessments (i.e., multistage quizzes/exams) as highly influential on their learning. The explanation for this could be at least two-fold. One possibility is that through this mechanism students had the chance to improve their grade, and it is possible that they could interpret a better grade as a signal that they achieved more learning, which ideally should be true but in reality may or may not be. On the 
other hand, multistage assessments pose an incentive system in which students not only have to examine their mistakes, but they also have the chance to improve them. It is known that there is a specific type of brain activity linking awareness of error to adaptive learning (Moser, Schroder, Heeter, Moran, \& Lee, 2011). Thus, it is possible that multistage assessments stimulate more of this type of brain activity, and, because of this, students' perception of learning increased. Students also perceived the class environment and instructor feedback to be highly influential on their learning. Barral and colleagues showed that a flipped classroom environment, in which students have more in-class time for activities by moving a large portion of content delivery outside of class, improved student performance in an introductory undergraduate biology course (Barral, Ardi-Pastores, \& Simmons, 2018). Additionally, mechanisms to facilitate cooperative learning within the classroom, for example through peer instruction and/or small group or team-based approaches, also improve student performance (Crouch \& Mazur, 2001; Goldberg \& Dintzis, 2007). Such a flipped model coupled with the incorporation of regular small group work was used in all courses examined in this study, which may thus explain why students perceived the class environment to have a relatively high influence on their learning. It would be remiss not to also mention the importance of instructor attitude and enthusiasm in the class environment, which captures attention thus improving recall and strongly correlates with student intrinsic motivation and vitality (Alsharif \& Qi, 2014; Moè, Frenzel, Au, \& Taxer, 2021). With respect to the influence of instructor feedback on student perceptions of learning, one can appreciate how the brain uses feedback to learn by considering some relevant analogies; artificial neural networks using learning algorithms rely on feedback to recognize patterns (Hopfield, 1987; Littman, 2015; Salam \& Bai, 1991), and iterative 
feedback mechanisms are used in machine and biological learning alike (Jones et al., 2009; Vates \& Nottebohm, 1995). Regarding its impact on learning, feedback needs to be timely, specific, and actionable to be most effective. The use of feedback to shape learning has been formalized often for example in the training of physicians (Wigton, Patil, \& Hoellerich, 1986). Formative assessment is a method that essentially increases the frequency with which students receive feedback (Rolfe \& McPherson, 1995; Sadler, 1989), and it is being used more often in higher education. About $80 \%$ of students in introductory undergraduate biology courses perceived that use of formative assessments had a positive influence on their learning, and roughly one-third of such students perceived that it specifically improved their learning (Brazeal, Brown, \& Couch, 2016). In the courses examined in this study, multiple mechanisms were used to facilitate frequent feedback to students, e.g., regular group work during which instructor feedback routinely followed in-class activities, and multistage assessments on which students received individualized comments, the majority of which were not judgments of correctness but rather involved use of inquiry, e.g., asking students how they can improve specific aspects of their work. Such practices may explain why students here perceived instructor feedback as highly influential on their learning. It would be of further interest to know why students perceived asynchronous remote discussion as least influential on their learning. One possible explanation is that asynchronous activities preclude the possibility for real-time instructor feedback. Given the challenges the global pandemic has posed for education, in addition to the increasing popularity of massive open online courses (MOOCs) that use asynchronous learning approaches, this data suggests caution for educators around the use of asynchronous methods while highlighting the importance of synchronous ones. 
Regarding the analysis of the factors influencing student perceptions of learning, one limitation is that the selection of such factors was mainly limited to those at play in courses using flipped and active learning approaches. Thus, it is unknown how other factors associated with more traditional approaches (e.g., lectures, single point assessments) would compare in terms of their relative influence on perceived learning within the same student population.

It was intriguing to find that there was no apparent correlation between the perceived amount effort and learning that students reported. Thus, the quantity and perceived difficulty of effort alone appears insufficient for students to perceive learning gains. Others have also observed a disconnect and even inverse relationship between effortful but effective approaches and student perceptions of learning (Deslauriers et al., 2019; Kirk-Johnson, Galla, \& Fraundorf, 2019). The apparent lack of relation (or potentially inverse relation) between students' effort and their perceived learning is somewhat counter-intuitive and surprising given that researchers have established a positive and direct link between effort and academic performance (Galla et al., 2014). If deliberate practice (effort) builds expertise (learning), why do students not always appear to recognize this? The leading explanation is that students can misinterpret increased mental effort as ineffective learning. This has important implications for students who wish to self-regulate their learning, requiring of them some metacognition around this disconnect. Instructors who employ such effortful "active" strategies can also help students avoid this misinterpretation trap by raising students' awareness of this issue early in their courses and when mental effort requirements are likely to be high. In contrast to how effort related to student perceptions of learning, the extent of pleasure that students reported during their course experience did correlate, albeit very weakly, with their perception of 
learning. Of course, correlation is not necessarily causal, and without further qualifying information to identify that to which student learning was attributed, one cannot conclude whether students' pleasure caused learning or vice versa or both. It has been demonstrated experimentally that acquiring knowledge can be emotionally pleasing, and this is more likely to occur when the knowledge acquired satisfies one's curiosity (Perlovsky, Bonniot-Cabanac, \& Cabanac, 2010); two salient examples include the tendency to prefer new music and that of infants for new foods (Gold, Pearce, Mas-Herrero, Dagher, \& Zatorre, 2019; Nicklaus, 2016). Thus, while there is evidence to suggest that learning causes pleasure, the extent to which this happened in this context is a complicated matter beyond scope and difficult to resolve.

Finally, general limitations of this study include the relatively small sample of students within the same institution, the lack of measures on actual student learning/performance, and possible differences in survey responders versus non-responders for which one cannot account. Since Colorado College is a small liberal arts institution at which class sizes are relatively small, with typically not more than 25 students in any given class, the factors studied here may not be entirely representative of dynamics at other (e.g., larger) institutions. Regardless, the general message here on what drives student confidence and their perception of learning is rooted in evidence and sound principles on which one can base efforts to improve student learning. 


\section{References}

Alsharif, N. Z., \& Qi, Y. (2014). A Three-Year Study of the Impact of Instructor Attitude, Enthusiasm, and Teaching Style on Student Learning in a Medicinal Chemistry Course. American Journal of Pharmaceutical Education, 78(7). doi: 10.5688/ajpe787132

Anderson, A. E., Justement, L. B., \& Bruns, H. A. (2020). Using real-world examples of the COVID-19 pandemic to increase student confidence in their scientific literacy skills. Biochemistry and Molecular Biology Education, 48(6), 678-684. doi: 10.1002/bmb.21474

Barral, A. M., Ardi-Pastores, V. C., \& Simmons, R. E. (2018). Student Learning in an Accelerated Introductory Biology Course Is Significantly Enhanced by a Flipped-Learning Environment. CBE-Life Sciences Education, 17(3). doi: 10.1187/cbe.17-07-0129

Boldt, A., Schiffer, A. M., Waszak, F., \& Yeung, N. (2019). Confidence Predictions Affect Performance Confidence and Neural Preparation in Perceptual Decision Making. Scientific Reports, 9(1). doi: 10.1038/s41598-019-40681-9

Brazeal, K. R., Brown, T. L., \& Couch, B. A. (2016). Characterizing Student Perceptions of and Buy-In toward Common Formative Assessment Techniques. CBE-Life Sciences Education, 15(4). doi: 10.1187/cbe.16-03-0133

Burns, D. D. (1981). Feeling Good: The New Mood Therapy. Penguin Books.

Cook, A. L., Snow, E. T., Binns, H., \& Cook, P. S. (2015). Self-reported student confidence in troubleshooting ability increases after completion of an inquiry-based PCR practical. Biochemistry and Molecular Biology Education, 43(5), 316-323. doi: 10.1002/bmb.20881

Crouch, C. H., \& Mazur, E. (2001). Peer Instruction: Ten years of experience and results. American Journal of Physics, 69(9). doi: 10.1119/1.1374249

Deslauriers, L., Schelew, E., \& Wieman, C. (2011). Improved Learning in a Large-Enrollment Physics Class. Science, 332(6031). doi: 10.1126/science.1201783

Deslauriers, Louis, McCarty, L. S., Miller, K., Callaghan, K., \& Kestin, G. (2019). Measuring actual learning versus feeling of learning in response to being actively engaged in the classroom. Proceedings of the National Academy of Sciences, 116(39). doi: 10.1073/pnas.1821936116

Ericsson, K. A., Krampe, R. T., \& Tesch-Romer, C. (1993). The Role of Deliberate Practice in the Acquisition of Expert Performance. Psychological Review, 100(3), 363-406.

Favazzo, L., Willford, J. D., \& Watson, R. M. (2014). Correlating Student Knowledge and Confidence Using a Graded Knowledge Survey to Assess Student Learning in a General Microbiology Classroom. Journal of Microbiology \& Biology Education, 15(2). doi: 10.1128/jmbe.v15i2.693

Flanagan, K. M., \& Einarson, J. (2017). Gender, Math Confidence, and Grit: Relationships with Quantitative Skills and Performance in an Undergraduate Biology Course. CBE-Life Sciences Education, 16(3). doi: 10.1187/cbe.16-08-0253

Freeman, S., Eddy, S. L., McDonough, M., Smith, M. K., Okoroafor, N., Jordt, H., \& Wenderoth, M. P. (2014). Active learning increases student performance in science, engineering, and mathematics. Proceedings of the National Academy of Sciences, 111(23). doi: 10.1073/pnas.1319030111

Galla, B. M., Plummer, B. D., White, R. E., Meketon, D., D’Mello, S. K., \& Duckworth, A. L. (2014). The Academic Diligence Task (ADT): assessing individual differences in effort on tedious 
but important schoolwork. Contemporary Educational Psychology, 39(4). doi: 10.1016/j.cedpsych.2014.08.001

Gaudet, A. D., Ramer, L. M., Nakonechny, J., Cragg, J. J., \& Ramer, M. S. (2010). Small-Group Learning in an Upper-Level University Biology Class Enhances Academic Performance and Student Attitudes Toward Group Work. PLOS ONE, 5(12). doi:

10.1371/journal.pone.0015821

Gold, B. P., Pearce, M. T., Mas-Herrero, E., Dagher, A., \& Zatorre, R. J. (2019). Predictability and Uncertainty in the Pleasure of Music: A Reward for Learning? The Journal of Neuroscience, 39(47). doi: 10.1523/JNEUROSCI.0428-19.2019

Goldberg, H. R., \& Dintzis, R. (2007). The positive impact of team-based virtual microscopy on student learning in physiology and histology. Advances in Physiology Education, 31(3). doi: 10.1152/advan.00125.2006

Hopfield, J. J. (1987). Learning algorithms and probability distributions in feed-forward and feed-back networks. Proceedings of the National Academy of Sciences, 84(23). doi: 10.1073/pnas.84.23.8429

Jones, T. R., Carpenter, A. E., Lamprecht, M. R., Moffat, J., Silver, S. J., Grenier, J. K., ... Sabatini, D. M. (2009). Scoring diverse cellular morphologies in image-based screens with iterative feedback and machine learning. Proceedings of the National Academy of Sciences, 106(6). doi: $10.1073 /$ pnas.0808843106

Kempton, C. E., Weber, K. S., \& Johnson, S. M. (2017). Method to Increase Undergraduate Laboratory Student Confidence in Performing Independent Research. Journal of Microbiology \& Biology Education, 18(1). doi: 10.1128/jmbe.v18i1.1230

Kepecs, A., Uchida, N., Zariwala, H. A., \& Mainen, Z. F. (2008). Neural correlates, computation and behavioural impact of decision confidence. Nature, 455(7210), 227-231. doi: 10.1038 /nature 07200

Kiani, R., \& Shadlen, M. N. (2009). Representation of confidence associated with a decision by neurons in the parietal cortex. Science, 324(5928), 759-764. doi: 10.1126/science.1169405

Kirk-Johnson, A., Galla, B. M., \& Fraundorf, S. H. (2019). Perceiving effort as poor learning: The misinterpreted-effort hypothesis of how experienced effort and perceived learning relate to study strategy choice. Cognitive Psychology, 115. doi: 10.1016/j.cogpsych.2019.101237

Kruger, J., \& Dunning, D. (1999). Unskilled and unaware of it: How difficulties in recognizing one's own incompetence lead to inflated self-assessments. Journal of Personality and Social Psychology, 77(6). doi: 10.1037/0022-3514.77.6.1121

Littman, M. L. (2015). Reinforcement learning improves behaviour from evaluative feedback. Nature, 521(7553). doi: 10.1038/nature14540

Moè, A., Frenzel, A. C., Au, L., \& Taxer, J. L. (2021). Displayed enthusiasm attracts attention and improves recall. British Journal of Educational Psychology, 91(3). doi: 10.1111/bjep.12399

Moser, J. S., Schroder, H. S., Heeter, C., Moran, T. P., \& Lee, Y.-H. (2011). Mind Your Errors: evidence for a neural mechanism linking growth mind-set to adaptive posterror adjustments. Psychological Science, 22(12). doi: 10.1177/0956797611419520

Nicklaus, S. (2016). The role of food experiences during early childhood in food pleasure learning. Appetite, 104. doi: 10.1016/j.appet.2015.08.022

Perlovsky, L., Bonniot-Cabanac, M.-C., \& Cabanac, M. (2010). Curiosity and Pleasure. ArXiv. 
Price, A. M., Kim, C. J., Burkholder, E. W., Fritz, A. v., \& Wieman, C. E. (2021). A Detailed Characterization of the Expert Problem-Solving Process in Science and Engineering: Guidance for Teaching and Assessment. CBE-Life Sciences Education, 20(3), ar43. doi: 10.1187/cbe.20-12-0276

Riedl, C., Kim, Y. J., Gupta, P., Malone, T. W., \& Woolley, A. W. (2021). Quantifying collective intelligence in human groups. Proceedings of the National Academy of Sciences, 118(21). doi: 10.1073/PNAS.2005737118

Rolfe, I., \& McPherson, J. (1995). Formative assessment: how am I doing? The Lancet, 345(8953). doi: 10.1016/S0140-6736(95)92968-1

Sadler, R. D. (1989). Formative assessment and the design of instructional systems. Instructional Science, 18, 119-144.

Salam, F. M. A., \& Bai, S. (1991). A new feedback neural network with supervised learning. IEEE Transactions on Neural Networks, 2(1). doi: 10.1109/72.80309

Vates, G. E., \& Nottebohm, F. (1995). Feedback circuitry within a song-learning pathway. Proceedings of the National Academy of Sciences, 92(11). doi: 10.1073/pnas.92.11.5139

Wigton, R. S., Patil, K. D., \& Hoellerich, V. L. (1986). The effect of feedback in learning clinical diagnosis. Academic Medicine, 61(10). doi: 10.1097/00001888-198610000-00006

Woolley, A. W., Chabris, C. F., Pentland, A., Hashmi, N., \& Malone, T. W. (2010). Evidence for a Collective Intelligence Factor in the Performance of Human Groups. Science, 330(6004). doi: $10.1126 /$ science.1193147

Zarnoth, P., \& Sniezek, J. A. (1997). The Social Influence of Confidence in Group Decision Making. The Journal of Experimental Social Psychology, 33, 345-366. 